\title{
Research on Development of Suburban Home Stay in Less Industrialized
} Area

\author{
Anmei Wang ${ }^{1 *}, Y u$ Wang ${ }^{2}$ \\ ${ }^{1}$ Toursim Management, Xianda College of Economics and Humanities Shanghai International Studies \\ University, No. 390, Dongtiyuhui Road, Shanghai China \\ ${ }^{2}$ Cultural Heritage Management, The University of Sheffield, Sheffield, The United Kingdom \\ *Corresponding author.
}

\begin{abstract}
Taking the advantage of rural vitalization strategy, homestay has become a powerful means for rural areas with less-developed secondary industry to explore industrial vitalization and transformation, thus achieving both economic growth and social development. Taking homestay in somewhere as an example, this paper goes through the existing bottleneck and risk to figure out suggestion and proposal for the better development of homestay industry, such as planning first, leveraging important activities to accelerate the growth, together with rural culture embedded.
\end{abstract}

Keywords:Homestay, suburb,industryvitalization

\section{Introduction}

Homestay being with unique accommodation and cultural experience, apart from traditional standardized hotel, is an innovation. In recent years, it has become a new accommodation mode, and been favored by the tourism market and investors, on the one hand, it can solve the problem of idle houses, especially, serve as powerful starting point for rural area to explore economic transformation and develop tourism economy. On the other hand, it can be good supply for the rigid demand in some popular locations where there is no adequate accommodation in peak time. On April 15, 2021, the General Office of the State Council called for the actions of "encouraging all regions to appropriately relax tourism accommodation market access to homestay and promoting the implementation of tourism accommodation industry standards".

Shanghai, as an ultra-mega city of China with 24.87 million permanent population (per 7 th national census), is one of most important global transportation hubs and touring cities. To enforce its tourism economy, in September 2018, Shanghai government issued the policy of "Some Suggestions on Promoting the Development of High Quality Tourism in Shanghai and Speeding up the Construction of World Famous Tourism City" which explicitly mentioned that tourism is an important starting point for Shanghai's "four major brands" and also an important driver for Shanghai city energy level and core competency. Thus, Shanghai suburban homestay should proactively join this great activity to deliver value of leisure and recreation. Meaning while, it is the good linkage between urban area and countryside for rural vitalization.

\section{Current Status of Suburban Homestay in Shanghai}

\subsection{Huge Potential Growth from a Late Start}

Whether it is compared to nationwide of the " three big homestay circles ": Zhejiang Mogan Mountain, Beijing and Yunnan province, or compared to the Yangtze River Delta region, Shanghai suburban homestay development is relatively late with less fame and influence in tourism market. While, Shanghai suburban homestay has the huge potential growth: Many available rural houses contain Shanghai-style cultural elements which is the big selling point to domestic and foreign tourist who want to experience the life of Shanghai resident ${ }^{[1]}$. In 2019, Shanghai government implemented a survey on several districts with pure agricultural area, it showed that about $20 \%$ 
farmer houses are idle, and $50 \%$ of farmer houses are semi-idle;30 \% of farmers are willing to offer idle houses for additional income.

Let us look at Pudong (where New International Exhibition Center, wild animal park and Disney land locate), before COVID-19 pandemic, there were more than 30 million tourists every year, however quite many of them just stopped over Pudong. Even in holiday,many tourists just took accommodation outside Pudong, thus it was a pain point for Pudong to keep "overnight" visitors. Now situation gets quite a bit better since Disneyland openness, millions of tourists came to Pudong. So as to Chongming, less tourists came to Chongming several years ago, but now many tourists come for ecological touring experience[2].

\subsection{Rural Vitalization Strategy as a Key Trigger}

The national strategy of rural vitalization provides the great support and acts as trigger to suburban homestay industry. In order to make full use of this huge policy benefit, homestay owner and local government have made a lot of efforts to drive the homestay growth. Even more, the suburban homestay becomes a new integrator of "primary industry" and "tertiary industry", to create lot of jobs for farmers, provide transformation of rural industries with backward production capacity.

Also it plays an important role to drive the environment improvement in rural area, and inherit the local culture. For example, some high tier homestay in QingPu district can provide not only food, entertainment, but leisure and local culture experience to attract more customers[3].

\subsection{Strong Promotion Effect by Well-known Scenic Spot or Important Festivals}

Well-known spots such as Disney and Haichang Ocean Park and the upcoming Ice and Snow World in Pudong, as well as the annual CIIE and the 10th Flower Expo, have created large promotion effect to tourism and homestay business. For example, the opening of Disneyland has stimulated homestay around Disneyland to grow at an annual rate of $20 \%$, from three or four homestay inn in 2016 to more than one thousand homestays till May 2021. Similar case occurs in Chongming, the homestay business makes great progress by taking the advantage of 10th Flower Expo.

\subsection{Management Standardization on Progress}

As a new business model, it is true that management standardization and policy are behind the industry development. This is also the case for Shanghai suburban homestay, for example, when Disneyland opened in 2016, the nearby homestay inns charged high price with insufficient service and incomplete facility, which caused quite lots of complaints. At that time, there was even no any standard for homestay industry as rule of judgement. Therefore, in 2016, the Pudong version of homestay standard -- "Pudong New District's Opinions on Promoting the Development of the Featured Homestay Industry (Trial)" was officially released, it chose three key homestay located areas which are villages nearby Disneyland, ancient town streets, and DaTuan peach park as pilot to foster homestay healthy development ${ }^{[4]}$. Then in June 2017, one notable achievement came out, Pudong issued its first homestay license. Later on in September 2018, the Shanghai Municipal Tourism Administration and the Municipal Agriculture Committee issued the guideline of "Guiding Opinions on Promoting the Development of Countryside Homestay" with the principle of "planning first, developing orderly, guided by government, participating marketwise". And then in November 2020, the national version of "Countryside Homestay Service Quality Standard" was officially promulgated, which has filled the gaps in countryside homestay management standard. Immediately afterwards, the Ministry of Culture and Tourism issued the standard of "Basic Requirements and Evaluation of Tourist Homestay" in February 2021, this means standardized homestay management has been on the right track[5].

\section{Problems of Shanghai Suburban Homestay}

3.1 Inadequate Infrastructure

ISSN: 0010-8189

(C) CONVERTER 2020 
The overall development is relatively at low level right now. On the one hand, the rural roads, medical care, parking lots and other infrastructures on which homestay development depends are still in poor conditions. On the other hand, many homestay inns are scattered and operated separately, therefore there is lacking brand and scale effect. All these factors restrain homestay development.

\subsection{Insufficient Return on Investment}

As a new form of accommodation, homestay growth is now at a rate of 10\%-20\%, while the average occupancy rate is only about 30\%, only in the Yangtze River Delta and the developed eastern coastal areas, the occupancy rate can reach $65 \%-70 \%$. However, the investment and operation cost of homestay is not less. According to estimation, the rent of a Shanghai suburban homestay inn with a size of $12 \sim 13$ rooms is about 80,000 yuan per year. If the leasing term is 5 years, then rent fee plus the decoration and labor cost, the initial investment would be $600,000-700,000$ yuan, which means the payback period is about 5 - 8 years. Plus, competition and the lack of branding channels, all of them has resulted in insufficient return on investment for many homestays, consequently affected its healthy development. Through the interviewing some homestay owners, it was found that many homestay inns are indeed struggling to survive, for example, the price of homestay around the Disneyland has been significantly cut down to 200 - 300 yuan from 400 - 600 yuan per night.

\subsection{Grade to Be Improved}

In general, the grade of Shanghai suburban homestay is still at low level, which makes it difficult to compete with homestay in Jiangsu and Zhejiang province. In recent years, through the idle houses in Shanghai suburb are mostly used as homestay inns, but most of them operate at low level; in addition, many farmers do not follow the spirit of contract, breaches of contract occur from time to time, which further weakens homestay development. Meaning while, some township cadres believe that homestay has little to do with enhancing the strength of the rural collective economy, also they worry about its "Zhetengand Short-term" then are unwilling to invest more resources. One more thing is that the boundary of higher-level management has not been clarified yet, as we all know, homestay is located in rural area, so it is under the jurisdiction of the Agricultural Commission, while, its function is under the jurisdiction of the Tourism Bureau, so sometimes it is difficult to delineate the clear boundary to result in case of "everyone is in charge, no one is in trouble".

\section{Suggestions for Shanghai Suburban Homestay Business}

Based on above analysis and summary, the author believes that it is better for Shanghai to learn advanced concepts and models at home and abroad, take the initiative to explore the way for homestay to deeply step into the rural economy and beautiful rural life journey by following the roadmap of rural vitalization and beautiful countryside strategy. As a new value creation model in the countryside, suburban homestay can not only create localized employment chance for farmer, but also can act as the lever to effectively promote the transformation of rural economy, improve the dualistic structure between urban and rural area[6].

\subsection{Following Rural Vitalization Strategy Closely to Make Top Level Plan}

Shanghai Suburban homestay need to closely follow the rural vitalization strategy, focus on the theme of ancient town, characterized villages to drive the development. Such as consolidating homestay inns belonging to one village as one unit to integrate tourism elements of food, accommodation and entertainment with local cultures. For this reason, a competent department should take the lead to strengthen coordination among multiple departments, integrate resources to form an effective coordination mechanism. For example, we can take a unified platform to coordinate environmental improvement and infrastructure construction to build batches of homestay inns with certain scale for tourists to relax and experience. Thus, it also becomes a good employment opportunity for rural resident.

\subsection{Features Pursuing and Branding}

ISSN: 0010-8189

(C) CONVERTER 2020 
Today, homestay is no longer the concept of accommodation during the travel, but the carriers of multiple consumption methods and diversified cultures. Therefore, the homestay industry needs to utilize the local unique environment and culture, or local characteristic industries to implement differentiation and brand building strategy. At the same time, we need to build up the training mechanism to cultivate a group of professional homestay owners for better operating. Together we can form the pattern of "one family, one product, one town, one specialty". For example, the homestay inns around Disneyland attract many young people through diversified projects and personalized user experience; Fengxian District has grown a number of good homestay inns featured as "Shanghai Style Jiangnan" and "Bay Ecology", now they become the business cards of rural tourism to "experience the charm of the countryside and assimilate into nature"[7].

\section{Chongming Homestay Overview}

\subsection{Chongming Basic Information}

Chong Ming Island is located at the outlet of the Yangtze River, the world's largest estuary alluvial island and the third largest island, in China. It accounts for roughly one-fifth of the land area of Shanghai with a humid climate and pleasant temperatures all year round. Chongming also has a long farming history,now it has one-third of arable land and one-fifth of the agricultural population of Shanghai, plays an important role of ecological barrier to ecological environment of the Yangtze River Delta and Yangtze River Basin, even for the whole country.

\subsection{Current Status of Chongming Homestay}

In general, despite of poor transportation, the development of Chongming homestay has developed rapidly by taking the advantage of "Good timeliness, Geographic convenience andHarmonious human relation". Good climate and geographical advantage endorse lots of ecological resources to Chongming, together with strong policy support, we now see more than 525 registered homestay inns on the island (according to data from the Shanghai Municipal Bureau of Culture and Tourism), which occupies $90 \%$ of all registered homestays in Shanghai. If you view Chongming homestay from the physical layout perspective, you will see 3 clusters currently located in the east, middle and west of the island, each cluster has similar style of homestay inn. While from the perspective of operation mode, you can have the idea of four categories: "Home B\&Bs", which are run by the villagers themselves; "farms" can be simply viewed as houses plus farm; the other two categories are morelarger which we callthem as "happy farm" and "village grouped homestay inn".

\subsubsection{Rapid Development on a Late Start}

As mentioned earlier, the development of Chongming Homestay started late, but it grow rapidly. An evidence is that: at the Chongming Homestay Industry Forum in August 2016, an expect of homestay bluntly stated that "the development of Chongming Homestay is still in its infancy", but only three years later, in September 2019, the Chongming Homestay Industry Association was founded. According to data from the Shanghai Municipal Bureau of Culture and Tourism, we also see the great progress, out of 579 registered homestay inns, 525 are in Chongming, accounting for $90 \%$ ! As of April 2021, the total number of homestay inns in Chongming increased to 700 . With Besides the rapid development, the overall grade of Chongming B\&Bs is also leading the way in Shanghai: per the assessment launched by Shanghai Tourism Resources Development Quality Evaluation Committee in 2019 and 2020, we know 48 out of the 70 star-rated countryside homestay inns are belonging to Chongming district, $70 \%$ in percentage. So, we are pretty sure that Chongming Homestay has more bright future.

\subsubsection{Specialized as Ecological Homestay with Great Policy Support}

Chongming, the "world-class ecological island", has unique natural resource endowment, such as the Dongtan wetland which is the bird paradise,Xisha wetland has natural special tide, and Dongping National Forest Park, which is the largest plain plantation in East China. When you come to Chongming countryside, you will see large number of homestay inns are surrounded by green trees and flowing water. This ecological advantage is so significant that the first national ecological homestay standard is called "Chongming Ecological Homestay Rating ISSN: 0010-8189 
Standard" issued in April 2018. As mentioned earlier, another advantage is harmonized human relationship, in Chongming, local government and villager are actively following the national strategies like "Rural vitalization", "Large protection of the Yangtze River", and "Integration of the Yangtze River Delta" to find innovation of the value creation for rural idle houses, which is mainly by developing homestay business. Recent years Local Government issued series of policies to support homestay business, such as "Support and Incentive Measures for Promoting the Development of Chongming Cultural Tourism Industry"(issued in 2020 to encourage the clustering and qualitative development of homestay); "Support Measures for Promoting the Construction of Accommodation and Catering Facilities in the Flower Expo"(to encourage investment in homestay accommodation and catering facility). In addition, with the continuous transportation construction, infrastructure projects such as the metro Chongming Line (kicked off) and the North Yangtze Riverside High-speed Railway will significantly eliminate current traffic disadvantage.

\subsubsection{Post COVID 19 Pandemic \& Flower Expo Stimulation}

Affected by the COVID 19 epidemic in 2020, homestay industry experienced a horrible period of desertion, more than many homestay inns shut down, while some homestay owners still viewed it as an opportunity, they took this period to innovate distinctive products with local rural culture embedded to attract more tourists. From homestay customer side, people now get used to normalized prevention and control practice after the epidemic, they have dramatically reduced long-distance travel plan and switched to go to nearby site for short distance tour in holidays or vacations. This trend has made Chongming homestay business booming again in late 2020. For example, no room could be booked even half a month before the National Day Holiday of 2020, and then same case to 2021 Spring Festival holiday, there was no chance to book a homestay during that time, all rooms were booked one month ago even before! Look at one data, according to the Chongming District Bureau of Culture and Tourism, the occupancy rate of star-rated homestay is close to $90 \%$ during the tomb sweeping holiday in 2021.

Another large activity for Chongming in this year is the 10th China Flower Expo. Known as the "Olympic" in China's flower industry, it will be held in Chongming from May to July, the first time for Flower Expo to be placed in village, island, and forest park. In order to take this great opportunity, Chongming's homestay stakeholders have carried out set of activities to improve the hardware and service quality. Nowadays, the "Flower Expo Home" effect has already emerged, more and more orders come in during these couple of months, so many homestay owners are confident that the occupancy rate during the Flower Expo will be up to $60 \%$.

5.2.4 Immature Industry and Lack of Talents

According to the Chongming District Culture and Tourism Bureau, the number of Chongming homestay inns has reached to 700 in 2021, it looks not small number, while it is not. As per the chairman of Chongming Homestay Association and the owner of "ZhiGu 1984" Liu Qing said: "The scale effect of homestay is very important, only when the number of homestay rated three-star or above in Chongming District reaches 1,000, and each homestay has an annual turnover no less than 1 million yuan, then this industry can be considered mature". In order to accelerate ecological homestay development, the Bureau of Chongming District Cultural Tourism has initiated some actions to setup no less than $200 \mathrm{mid}$ or high-tier homestay inns by taking the opportunity of the 2021 Flower Expo.

In March 2021, the author had a discussion with Zhang Jinsong who is the master of Dongtan Station of Chongming Homestay Association, also the owner of the well-known homestay inn named "Hou Yuan", he mentioned that: currently most homestay inns in Chongming are in large shortage of professional talents. For example, the personnel who provide daily services are basically from local residents who most likely have not received any professional training. And as for homestay owners, they also act as homestay inn manager, often time they do not have homestay operation experience. Evenmore many small homestay owners take homestay as a family sideline. From talent pool perspective, the existing pipeline is also mainly aimed at traditional accommodation industries like hotel. As the homestay continues to grow with more standardized requirement, this problem will become more and more visible and serious.

\subsection{Suggestion for Development of Chongming Homestay}

\subsubsection{Upper-level Roadmap and Foundation Strengthening Plan}

ISSN: 0010-8189

(C) CONVERTER 2020

www.converter-magazine.info 
Till now, Chongming homestay industry is still without upper-level roadmap. Referring to the 14th Five-Year Plan for Chongming District which was released recently, we cannot find the term "homestay" even. While the upper-level roadmap is so important that it leads the way, shows us the big picture and outline. Thus, all the market entities can be fully motivated and all resources could be integrated together, which is the key to better development of the entire industry. As the chairman of Chongming Homestay Association said: "at present, there are almost one hundred homestay projects to be launched or launched already in Chongming, down the road, there will be still a lot of difficulties and bottlenecks, so let us gather as a group to share the resources, reduce risk, and interact with each other, help each other". On the other hand, Chongming Homestay industry can simulate the concept of national "Strengthening Foundation" plan (strengthening basic subjects) to implement its own "Strengthening Foundation" plan, which could be taking "ecology" as the basic subject to strengthen this foundation. This way the stakeholders will focus on this to do marketing, build ecology as golden sign of Chongming homestay.

\subsubsection{Taking Boutique Route}

As a highly personalized product, homestay emphasizes interaction among people, facility and environment, therefore you need to take boutique as your homestay goal, by thinking your customer to well design your homestay, such as reception service, catering facility and appliances, since all these factors determine the customer satisfaction and the value creation process. Looking at all successful operating homestay inns in Chongming, there is no exception, they all perform well to meet tourist requirement from Shanghai or Yangtze River Delta who have strong purchase power and are willing to pay a premium for the experience or service they value ... Many homestay inns have already developed multiple functions to incorporate cultural and recreative elements such as yoga, Chongming homespun, tea ceremony and baking, as a return, they achieved very good economic and social benefits. It goes without saying that Chongming homestay should take the route of boutique for better and long-term development.

\section{Acknowledgements}

This research was supported by Research on the High-quality Development of Rural Tourism in ChongmingBased on RMP Analysis (Grant No.A3023.20.002).

\section{Reference}

[1] S. Ling. "Fostering characteristic homestays to promote rural revitalization," Shanghai Rural Economy, vol. 3, pp. 12-14, 2020.

[2] H. Chai. "Current situation," Problems and Countermeasures of Homestay Development in Shanghai.Scientific Development,vol. 10, pp. 104-113, 2019.

[3] H. Wang. "Building shencheng characteristic lodging industry," Shanghai Rural Economy, vol. 1, 27, 2019.

[4] Z. Q. Chen. "What does homestay bring to the countryside - interview with the first pilot homestay in shanghai pudong new area,"Shanghai Rural Economy, vol. 10, pp. 14-17, 2018.

[5] D.Hao. "A preliminary study on the development and legal regulation of b \&b in shanghai," Tourism Overview, vol. 1, pp. 72-73, 2018.

[6] J. Shen, J. Y. Zhou, W. Y. Wang. "The development path of domestic and foreign residential quarters and the development strategy of residential quarters in shanghai suburbs," Scientific Development,vol. 5, pp. 43-51, 2017.

[7] S. H. Liu. "Pudonghomestay: retaining rural culture and nostalgia,"Pudong Developing,vol. 2, pp. 10-11, 2017. 